\author{
Wacław Szcześniak \\ prof. dr inż. \\ Wydział Budownictwa i Architektury \\ Politechnika Lubelska \\ w.szczesniak@il.pw.edu.pl \\ Magdalena Ataman \\ dr inż. \\ Wydział Inżynierii Lądowej \\ Politechnika Warszawska \\ m.ataman@il.pw.edu.pl
}

DOI: 10.35117/A_ENG_17_09_07

Moving oscillator on the floating bridge

\begin{abstract}
The paper deals with vibration analysis of three span floating bridge under moving oscillator. Velocity of the oscillator is constant. Forced and free vibrations of pontoon bridge are discussed. Three equations of motion of the system for each span are solved numerically. Solution of damped vibrations and solution for undamped vibrations are presented. Some results are shown in the Figures 3-9.
\end{abstract}

Keywords: Floating bridge; Viscoelastic moving oscillator; Forced and free vibrations

\title{
Introduction and formulation of the problem
}

Issues related to the statics and dynamics of floating bridges are not new in the rich literature of the subject [1]]. Floating bridges are included in makeshift structures, built for specific purposes for special tasks and have a limited lifetime. The speed of vehicles moving on such facilities is generally limited to a maximum of a dozen or so $\mathrm{km} / \mathrm{h}$.

In this study, the vibrations of such constructions forced by a moving mono magnetic viscoelastic oscillator moving at a constant speed will be analyzed. The three-span bridge is modeled by a system with two degrees of laxity, the oscillator has an additional degree of laxity. Mathematically, the task is a system of three coupled, differential equations of motion, due to the time variable, describing the vibrations of two pontoons that are movable props of the bridge and oscillating motion of the oscillator.

\section{The issue of floating bridge}

The three-span floating bridge modeled in a simplified way consists of three rigid plates, each with a total weight $m$ and length $l$. The mass of each of the two floatings, together with the coiling water, is equal $M$ and the horizontal cross-section of the $F$ is equal. In the static equilibrium position, the bridge plates are horizontal as in Figure 1. The density of water is denoted by $\rho$. 


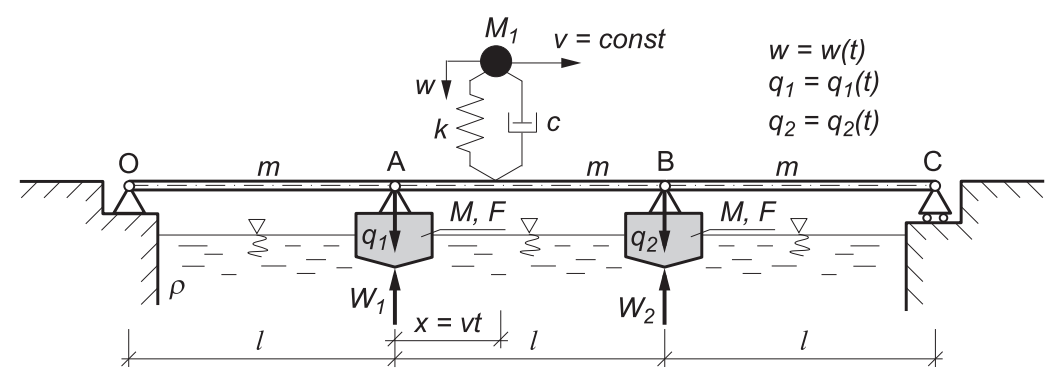

1. Dynamic scheme of the task

The task has two degrees of laxity, according to Figure 1, as the generalized Lagrangian coordinates, we assume two vertical displacements of pontoons $\mathrm{A}$ and $\mathrm{B}$, respectively $q_{1}$ and $q_{2}$. First of all, we will determine the circular frequencies of the bridge's own vibrations and determine the forms of its own vibrations. The equations of the motion of the analyzed bridge can be derived e.g. using the Lagrange second order equations [11]. Assuming that the water resistance forces are proportional to the generalized coordinates $q_{1}$ and $q_{2}$ :

$W_{1}=F \rho g q_{1}, \quad W_{2}=F \rho g q_{2}$,

we get the following equations

$\frac{1}{6}(4 m+6 M) \ddot{q}_{1}+\frac{1}{6} m \ddot{q}_{2}+F \rho g q_{1}=0$,
$\frac{1}{6} m \ddot{q}_{1}+\frac{1}{6}(4 m+6 M) \ddot{q}_{2}+F \rho g q_{2}=0$.

Two circular frequencies, own values and own vectors (forms of vibrations - mods) can be found using the MATHEMATICA "EigenSystem" instruction, from where we get:

$\omega_{1}=\sqrt{\frac{F \rho g}{M+\frac{5}{6} m}}, \quad \omega_{2}=\sqrt{\frac{F \rho g}{M+\frac{1}{2} m}}$,

$\{1,1\}, \quad\{-1,1\}$,

$\left\{\left(M+\frac{5}{6} m\right)+F \rho g\right\}, \quad\left\{\left(M+\frac{5}{6} m\right)+F \rho g\right\}$.

Figure 2 shows two forms of the bridge's own vibrations and the corresponding circular frequencies.
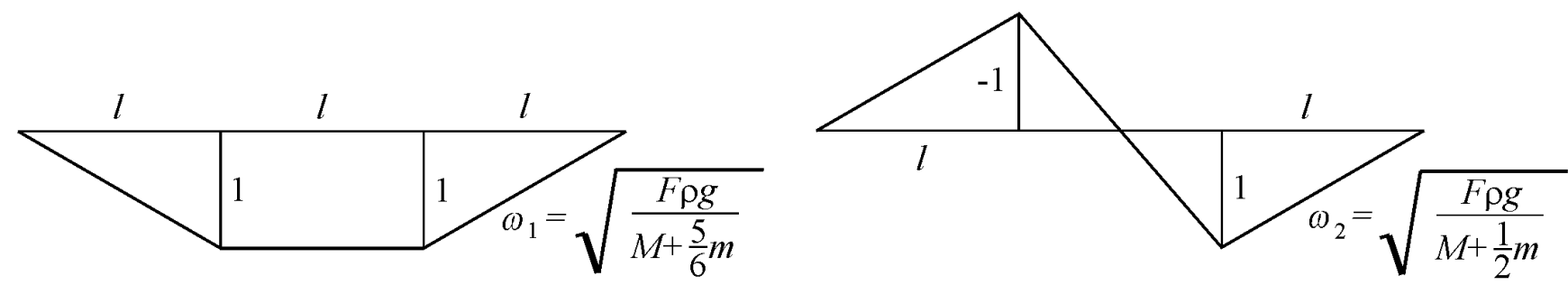

2. The forms of the bridge's own vibrations

Bridge undamped vibrations under a moving oscillator 
In this chapter we will determine the undamped vibrations of the bridge forced by the passage of a moving, visco-elastic one-mass oscillator. We will also discuss free vibrations after the oscillator's exit from the pontoon bridge. The speed of the mobile oscillator is constant and is equal. We are dealing with a material system with three degrees of laxity $w, q_{1}$ and $q_{2}$ (Figure 1).

Dynamic pressure of the oscillator $N(t)$ on the span plate we define from the motion equation of the oscillator:

$N(t)=M_{1} g-M_{1} \frac{\mathrm{d}^{2} w}{\mathrm{~d} t^{2}}$.

If by $\widetilde{w}$ we will mark the deflection of the bridge carriageway directly at the point of contact between the oscillator and the plate, then the oscillator motion equation is as follows:

$$
\begin{aligned}
& M_{1} \frac{\mathrm{d}^{2} w}{\mathrm{~d} t^{2}}+c\left(\frac{\mathrm{d} w}{\mathrm{~d} t}-\frac{\mathrm{d} \tilde{w}}{\mathrm{~d} t}\right)+k(w-\tilde{w})=0, \\
& \frac{\mathrm{d} \tilde{w}(v t, t)}{\mathrm{d} t}=\left.\frac{\partial \tilde{\mathrm{w}}}{\partial t}\right|_{x=v t}+\left.v \frac{\partial \tilde{\mathrm{w}}}{\partial x}\right|_{x=v t}, \\
& x=v t, \quad \frac{\tilde{w}}{v t}=\frac{q_{1}}{l} \rightarrow \quad \tilde{w}=\frac{q_{1}}{l} v t=\frac{q_{1}}{l} x, \quad \dot{\tilde{w}}=\frac{\dot{q}_{1}}{l} v t+\frac{q_{1}}{l} v .
\end{aligned}
$$

Finally, the motion equation of the oscillator in the first span of the pontoon bridge is in the form:

$$
M_{1} \frac{\mathrm{d}^{2} w}{\mathrm{~d} t^{2}}+c \frac{\mathrm{d} w}{\mathrm{~d} t}+k w=c\left(\frac{v t}{l} \frac{\mathrm{d} q_{1}}{\mathrm{~d} t}+\frac{q_{1}}{l} v\right)+k \frac{q_{1}}{l} v t .
$$

The equations of the motion of free damped vibrations (5) will now contain additional words from the forced $N(t)$ force. Therefore, the system of three differential ordinary traffic equations can be written in the following way:

$$
\begin{aligned}
& \frac{1}{6}(4 m+6 M) \ddot{q}_{1}+\frac{1}{6} m \ddot{q}_{2}+F \rho g q_{1}=\left(M_{1} g-M_{1} \frac{\mathrm{d}^{2} w}{\mathrm{~d} t^{2}}\right) \frac{v t}{l}, \\
& \frac{1}{6} m \ddot{q}_{1}+\frac{1}{6}(4 m+6 M) \ddot{q}_{2}+F \rho g q_{2}=0, \\
& M_{1} \ddot{w}+c \dot{w}+k w=c\left(\frac{\dot{q}_{1}}{l} v t+\frac{q_{1}}{l} v\right)+k \frac{q_{1}}{l} v t .
\end{aligned}
$$

The system of coupled motion equations is in total a sixth order relative to time. In order to uniquely describe the movement, six initial conditions must be formulated, which in this case are zero:

$$
w(0)=0, \quad q_{1}(0)=0, \quad q_{2}(0)=0, \quad \dot{w}(0)=0, \quad \dot{q}_{1}(0)=0, \quad \dot{q}_{2}(0)=0 .
$$

If the oscillator is in the second span, then the equations of motion are more complicated: 


$$
\begin{aligned}
& \frac{1}{6}(4 m+6 M) \ddot{q}_{1}+\frac{1}{6} m \ddot{q}_{2}+F \rho g q_{1}=\left(M_{1} g-M_{1} \frac{\mathrm{d}^{2} w}{\mathrm{~d} t^{2}}\right) \frac{l-v t}{l}, \\
& \frac{1}{6} m \ddot{q}_{1}+\frac{1}{6}(4 m+6 M) \ddot{q}_{2}+F \rho g q_{2}=\left(M_{1} g-M_{1} \frac{\mathrm{d}^{2} w}{\mathrm{~d} t^{2}}\right) \frac{v t}{l}, \\
& M_{1} \ddot{w}+c \dot{w}+k w=c\left(\dot{q}_{1} \frac{l-v t}{l}-q_{1} \frac{v}{l}+\dot{q}_{2} \frac{v t}{l}+q_{2} \frac{v}{l}\right)+k\left(q_{1} \frac{l-v t}{l}+q_{2} \frac{v t}{l}\right),
\end{aligned}
$$

the deflection of the beam at the point of contact with the oscillator is now equal

$$
\tilde{w}=q_{1} \frac{l-v t}{l}+q_{2} \frac{v t}{l}, \quad \dot{\tilde{w}}=\dot{q}_{1} \frac{l-v t}{l}-q_{1} \frac{v}{l}+\dot{q}_{2} \frac{v t}{l}+q_{2} \frac{v}{l} .
$$

The initial conditions are no longer zero for the system of motion equations (9), they are determined by the solution of the system of equations (7) at the moment $t=\frac{l}{v}$.

If the oscillator is on the third span, the deflection under the oscillator and the system of motion equations are as follows:

$$
\begin{aligned}
& \tilde{w}=\frac{l-v t}{l} q_{2}, \quad \dot{\tilde{w}}=-q_{2} \frac{v}{l}+\frac{l-v t}{l} \dot{q}_{2}, \\
& \frac{1}{6}(4 m+6 M) \ddot{q}_{1}+\frac{1}{6} m \ddot{q}_{2}+F \rho g q_{1}=0, \\
& \frac{1}{6} m \ddot{q}_{1}+\frac{1}{6}(4 m+6 M) \ddot{q}_{2}+F \rho g q_{2}=\left(M_{1} g-M_{1} \frac{\mathrm{d}^{2} w}{\mathrm{~d} t^{2}}\right) \frac{l-v t}{l}, \\
& M_{1} \ddot{w}+c \dot{w}+k w=c\left(-\frac{v}{l} q_{2}+\frac{l-v t}{l} \dot{q}_{2}\right)+k \frac{l-v t}{l} q_{2} .
\end{aligned}
$$

Also in the third span, the initial conditions are not zero, but determined from the solution of the system of equations (9) at the moment $t=\frac{l}{v}$.

If the oscillator descends from the bridge and moves on an infinitely rigid, horizontal ground, the equations of the bridge's motion are homogeneous and describe free vibrations:

$$
\begin{aligned}
& \frac{1}{6}(4 m+6 M) \ddot{q}_{1}+\frac{1}{6} m \ddot{q}_{2}+F \rho g q_{1}=0, \\
& \frac{1}{6} m \ddot{q}_{1}+\frac{1}{6}(4 m+6 M) \ddot{q}_{2}+F \rho g q_{2}=0, \quad M_{1} \ddot{w}+c \dot{w}+k w=0 .
\end{aligned}
$$

The initial conditions in this case determine the solution of the system of equations (11) at the moment $t=\frac{l}{v}$. Therefore, we have a set of equations of the bridge's motion, which should be solved in order to determine the movement of the oscillator and the vertical displacements of the pontoons $q_{1}$ and $q_{2}$. 
The equations of motion (7), (9), (10) and (11) are solved numerically, taking the following numerical data: $m=5000 \mathrm{~kg}, M=2000 \mathrm{~kg}, M_{1}=1500 \mathrm{~kg}, k=150000 \mathrm{~N} / \mathrm{m}, c=0,05 c_{k r}$, $c_{k r}=2 \sqrt{M_{1} k}, \rho=1000 \mathrm{~kg} / \mathrm{m}^{3}, \quad l=30 \mathrm{~m}, \quad F=5 \mathrm{~m}^{2}, \quad v=10 \mathrm{~m} / \mathrm{s} \quad$ i $g=9,81 \mathrm{~m} / \mathrm{s}^{2}$. With given numerical values, the basic dynamic quantities are equal:

$$
\begin{aligned}
& \omega_{1}=\sqrt{\frac{F g \rho}{M+\frac{5}{6} m}}=2,82 \mathrm{~s}^{-1}, \quad \omega_{2}=\sqrt{\frac{F g \rho}{M+\frac{1}{2} g}}=3,3 \mathrm{~s}^{-1}, \\
& q_{s t}=\frac{\left(m+M+M_{1}\right) g}{F g \rho}=1,7 \mathrm{~m}, \quad q_{o s c}=\frac{M_{1} g}{k}=0,098 \mathrm{~m}, \\
& v_{k r 1}=\frac{\omega_{1} l}{\pi}=26,93 \mathrm{~m} / \mathrm{s}, \quad v_{k r 2}=\frac{\omega_{2} l}{\pi}=31,53 \mathrm{~m} / \mathrm{s} .
\end{aligned}
$$

Figures 3-9 show some results of the solution of four systems of equations of motion of the bridge (7), (9), (11) and (12). In all figures, displacements are given in meters, displacements velocity in meters per second, and time in seconds. To obtain real values $q$ of displacements, the volumes should be divided by static deflections of pontoons $q_{s t}$. Attention should be paid to the effect of moving down the mobile oscillator from the bridge, causing very large amplitudes of free vibrations due to the relatively small difference between the speed $v$ and the first critical speed.
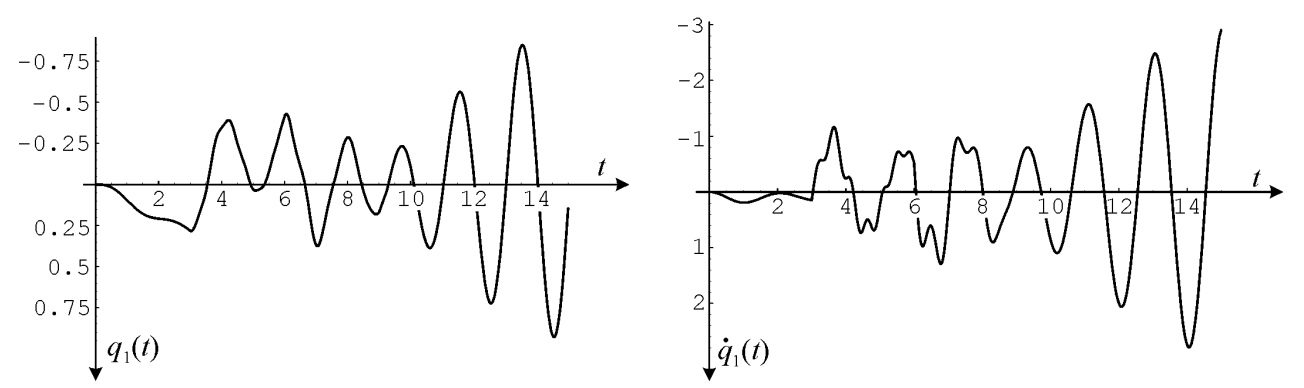

3. Vertical displacement charts $q_{1}(t)$ in [m] and speed $\dot{q}_{1}(t)$ the pontoon A in the absence of vibration damped by forced pontoons
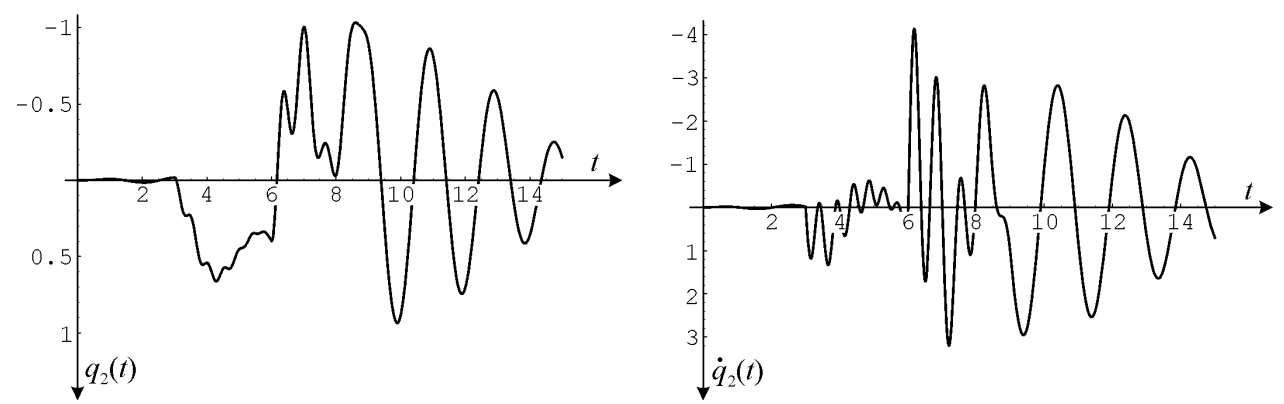

4. Vertical displacement charts $q_{2}(t)$ and speed $\dot{q}_{2}(t)$ the pontoon B in the absence of vibration damped by forced pontoons 

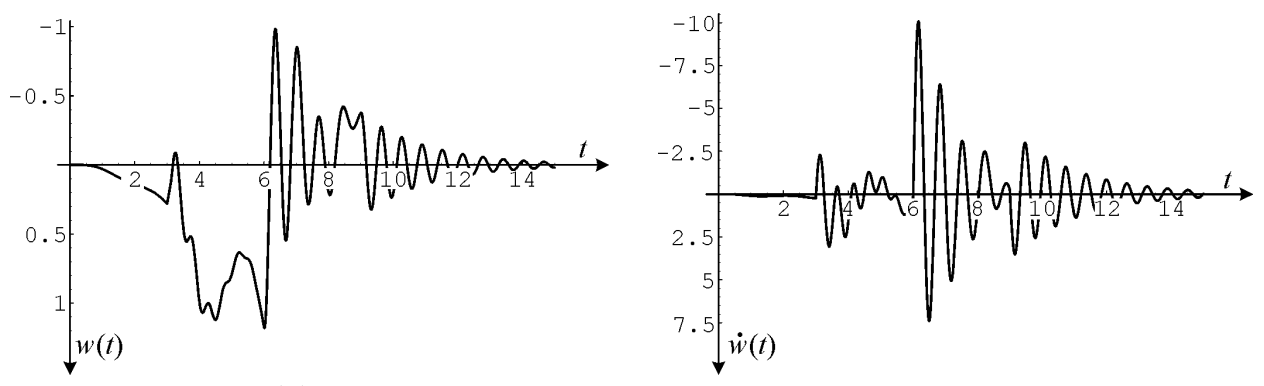

5. Deflection graph $w(t)$ a mobile oscillator and a graph of the deflection derivative $\dot{w}(t)$
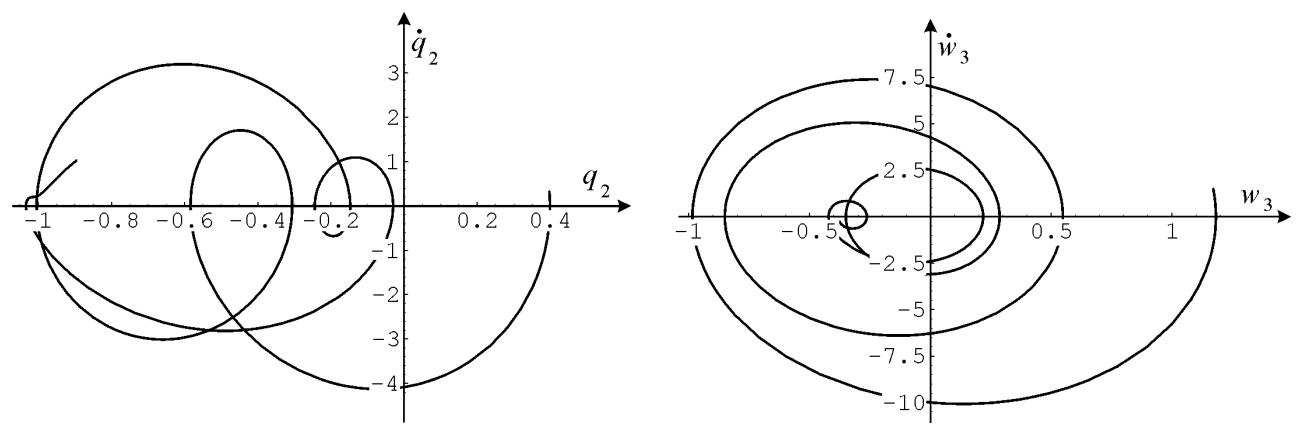

6. Coordinate phase portraits $q_{2}(t)$ and $w(t)$, the oscillator is in the third span
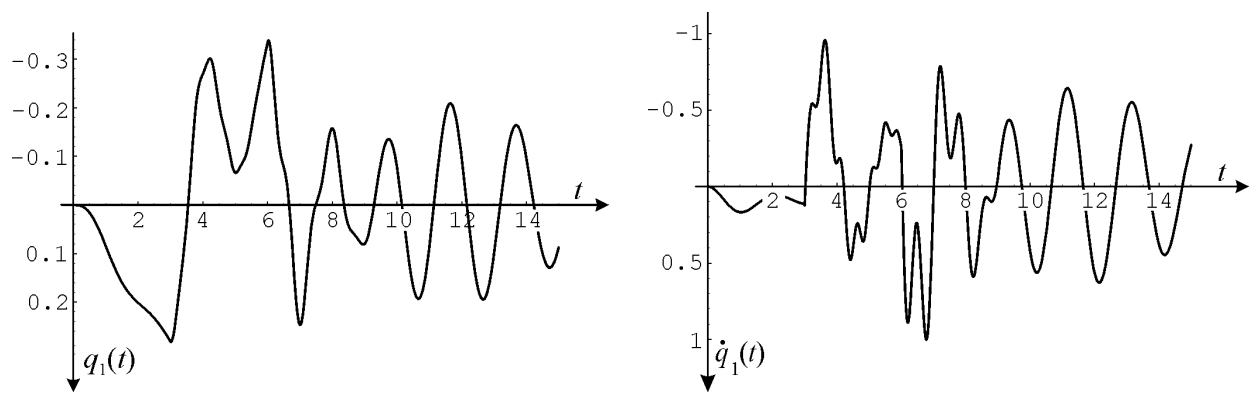

7. Vertical displacement charts $q_{1}(t)$ and speed $\dot{q}_{1}(t)$ pontoon A including damped vibrations of forced pontoons, $\beta=0,1 \beta_{k r}$
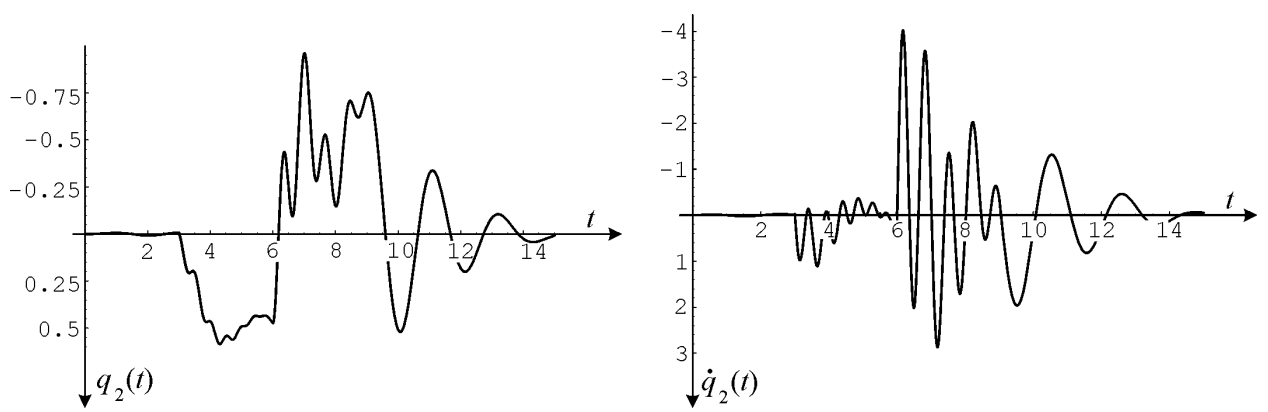

8. Vertical displacement charts $q_{2}(t)$ and speed $\dot{q}_{2}(t)$ pontoon B including damped vibrations of forced pontoons, $\beta=0,1 \beta_{k r}$ 

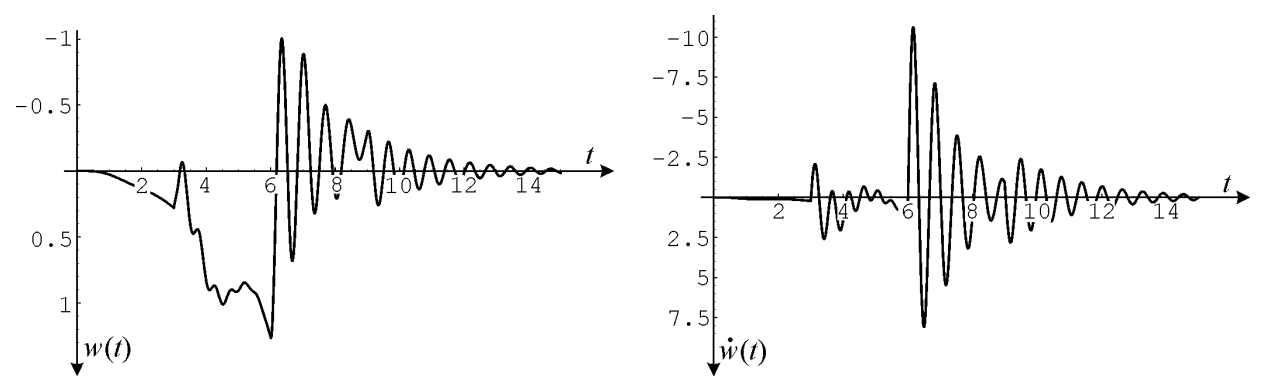

9. Deflection graph $w(t)$ a mobile oscillator and a graph of the deflection derivative $\dot{w}(t)$ including vibration damping of forced pontoons, $\beta=0,1 \beta_{k r}$

\section{Bridge damped vibration under a moving oscillator}

In the case of damped vibrations in the bridge motion equations, additional damping forces should be taken into account, proportional to the speed of the pontoons. In the case of damped vibrations in the bridge motion equations, additional damping forces proportional to the speed of the pontoons should be taken into account $\dot{q}_{1}$ and $\dot{q}_{2}$ :

$R_{1}=\beta \dot{q}_{1}, \quad R_{2}=\beta \dot{q}_{2}$,

$\beta$ is a fraction of the critical attenuation coefficient that we assume is constant, i.e. as in the case of a system with one degree of laxity

$$
\beta_{k r}=2 \sqrt{\frac{1}{3} F g(3 M+2 m)} .
$$

After taking into account the suppression of the motion equation of the bridge-oscillator system, when the oscillator is in the first span, they have the form:

$$
\begin{aligned}
& \frac{1}{6}(4 m+6 M) \ddot{q}_{1}+\frac{1}{6} m \ddot{q}_{2}+F \rho g q_{1}+\beta \dot{q}_{1}=\left(M_{1} g-M_{1} \frac{\mathrm{d}^{2} w}{\mathrm{~d} t^{2}}\right) \frac{v t}{l}, \\
& \frac{1}{6} m \ddot{q}_{1}+\frac{1}{6}(4 m+6 M) \ddot{q}_{2}+F \rho g q_{2}+\beta \dot{q}_{2}=0, \\
& M_{1} \ddot{w}+c \dot{w}+k w=c\left(\frac{\dot{q}_{1}}{l} v t+\frac{q_{1}}{l} v\right)+k \frac{q_{1}}{l} v t .
\end{aligned}
$$

Similarly, damping in systems of equations (9) and (11) should be taken into account, describing the vibrations of the bridge when the oscillator is located on the second and third spans, respectively.

The systems of equations obtained in this way are solved analogously to the previous task without taking into account damping, using in each case six initial conditions. As before, the initial conditions are zero only when the oscillator is on the first span, the subsequent initial conditions result from the solution for the previous span at the moment $t=\frac{l}{v}$. Based on the solutions received in this way, taking data as in the previous example and assuming in addition $\beta=0,1 \beta_{k r}$, charts are shown in the figures 7-9. 


\section{Conclusions and generalizations}

The paper discusses the dynamic solution of a three-span floating bridge loaded with a movable, single-mass visco-elastic oscillator. The speed of the oscillator is constant and relatively low, it was assumed to be equal to $10 \mathrm{~m} / \mathrm{s}$. Voltage and free vibrations were considered after the oscillator's exit from the bridge. A linear system of three traffic equations was solved numerically using the Mathematica code. The results of solutions for motion equations are shown graphically in Figures 4-9. The next stage of the studies regarding the dynamics of pontoon bridges will be to consider the effect of flexible bridge spans with finite bending stiffness. We will then have to deal with a discrete continuous system. The results of the study can be used to test computer calculations in FEM real constructions of folding bridges with intermediate floating supports.

\section{Source materials}

[1] Białobrzeski T. Mosty składane. WKit, Warszawa 1978.

[2] Bursztynowski Z. Mosty pływające na oddzielnych podporach. WAT, Warszawa 1988.

[3] Bursztynowski Z. Mosty składane. Podstawy obliczeń. PWN, Warszawa 1985.

[4] Krasoń W., Derewońko A., Chłus K., Kozłowski R. Analiza wytrzymałościowa odcinka prototypowego mostu pontonowego. Modelowanie Inżynierskie 44, Gliwice 2012, 151158.

[5] Marszałek J. Mosty składane. Projektowanie, badania i eksploatacja. Podręcznik GDDKiA i WAT, Warszawa 2005.

[6] Marszałek J., Piechota M. Analiza statyczna wieloprzęsłowych mostów składanych przy różnych warunkach podparcia. Biuletyn WAT, 2013, Vol. LXII, Nr 2, 167-180.

[7] Osama El-Desouky. I. M. Dynamic Behaviour of Short-Term Floating Bridge. Carleton Institute, Ottawa Canada 2011.

[8] Seif M.S., Inoue Y. Dynamic analysis of floating bridges. Marine Structures, 1998, Vol. 11, 29-46.

[9] Sterner W. Mosty Warszawy. PWT, Warszawa 1960.

[10] Szcześniak W. Dynamika teoretyczna dla zaawansowanych. OW PW, Warszawa 2007.

[11] Szcześniak W., Ataman M. Analiza dynamiczna mostu pontonowego. Theoretical Foundations of Civil Engineering, 2007, Vol. 15, OWPW, 635-644.

[12] Szcześniak W., Ataman M., Zbiciak A. Drgania belki sprężystej wywołane ruchomym, liniowym oscylatorem jednomasowym. Drogi i Mosty 2/2002, str. 53-83.

[13] Wieczorek M., Krasoń W. Obliczanie mostów pływających modelowanych elementami sztywnymi. Theoretical Foundations of Civil Engineering, Ed. W. Szcześniak, 1999, Vol. 6, OWPW, 357-364.

[14] Wu J.S, Lee M.S. Lai T.S. The dynamic analysis of a float plate under a moving load by the finite element method, International Journal for Numerical Methods in Engineering, 1987, 24, 743-762.

[15] Wu J.S., Shih P.Y. Moving-load-inducted vibration of a moored floating bridge. Computer and Structures, 1998, Vol. 66, No. 4, 435-461.

[16] Zhang J., Miao G.P., Liu J.X., Sun W.J. Analytical Models of floating bridges subjected by moving load for different water depths. Journal of Hydrodynamics, 2008, Vol. 20, No. 5, 537-546. 